\title{
Análise empírica do impacto econô- mico da ALCA e da consolidação do Mercosul sobre o Brasil
}

André Filipe Zago de Azevedo ${ }^{1}$

Flávio Tosi Feijó ${ }^{2}$

Resumo: Este artigo analisa o impacto da criação da ALCA e do aprofundamento do Mercosul sobre os fluxos de comércio, PIB e bem-estar sobre o Brasil e seus parceiros do bloco através do modelo de equilíbrio geral computável Global Trade Analysis Project (GTAP). A primeira simulação examina os efeitos econômicos da formação da ALCA entre 1995 (equilíbrio inicial) e 2016 (ano da consolidação do bloco) supondo a formação de uma Zona de Livre Comércio em 2016. A segunda simulação analisa os efeitos do estabelecimento da Tarifa Externa Comum (TEC) do Mercosul em 2006. O Brasil se beneficia com as duas situações, no que se refere a ganhos de bem-estar, com a formação da ALCA trazendo benefícios marginalmente superiores à consolidação do Mercosul.

Palavras-chave: Modelos de Equilíbrio Geral; Integração Regional; ALCA; Mercosul.

\section{Empirical analysis of the economic impact from ALCA and Mercosul consolidation on Brazil}

Abstract: This paper analyses the impact of the FTAA creation and the deepening
of Mercosul on trade flows, GDP and welfare in Brazil and its Mercosur partners
based on a computable general equilibrium model from the Global Trade Analysis
Project (GTAP). The first simulation examines the economic effects of the FTAA
formation between 1995 (initial equilibrium) and 2016 (year of consolidation of
the bloc) supposing the establishment of a Free Trade Area in 2016. The second
simulation analyses the effects of the establishment of Mercosul's common external
tariff (CET) in 2006. Brazil benefits from both scenarios with regards to welfare
1 Coordenador do Mestrado em Economia da Universidade do Vale do Rio dos Sinos (UNISINOS), e-mail:
aazevedo@unisinos.br; Endereço: Av. Unisinos, 950, sala 5A 410, São Leopoldo, RS, 93022-ooo.
2 Professor Adjunto da Fundaçâo Universidade Federal de Rio Grande (FURG), e-mail: tosifl@yahoo.com.br 
gains, with FTAA formation bringing benefits marginally higher than the deepening of Mercosul.

Keywords: General Equilibrium Models; Regional Integration; FTAA; Mercosul.

JEL: C68, F13, F15

\section{Introdução}

O ressurgimento de acordos preferenciais de comércio (APC) tem sido uma das características mais marcantes dos últimos anos. Este fenômeno, denominado de segunda onda de regionalismo, em contraste com a primeira onda de acordos regionais ocorrida nas décadas de 1950 e 1960, atinge quase a totalidade dos países integrantes da Organização Mundial de Comércio (OMC), já sendo responsável por cerca de um terço do comércio mundial, de acordo com o Banco Mundial (2000). ${ }^{3}$ Embora a estrutura dos blocos preferenciais varie profundamente, todos têm um objetivo comum: a redução das barreiras comerciais entre seus membros. Ao seu nível mais simples, os blocos comerciais somente eliminam as tarifas no comércio intrabloco, mas muitos cobrem também a redução de barreiras não tarifárias. A seu nível mais profundo, eles envolvem a formação de uma união econômica entre seus membros, com a criação de instituições executivas, judiciais e legislativas comuns.

A maior parte destes acordos envolve países com níveis de desenvolvimento econômico semelhantes. Mais recentemente, porém, países desenvolvidos e em desenvolvimento têm firmado acordos regionais entre si, caso típico da Área de Livre Comércio da América do Norte (NAFTA) e de acordos realizados entre a União Europeia e países do Leste Europeu. O Brasil, que também tem buscado aprofundar a integração regional com seus parceiros do Mercosul, já firmou compromisso de negociar seu ingresso, através de negociações isoladas ou em conjunto com os demais países do Mercosul, no que virá a ser a Área de Livre Comércio das Américas (ALCA). Este bloco visa eliminar as tarifas de importação de bens e serviços de todos os países do continente americano, com exceção de Cuba, entre 2006 e 2016. Mas, quais serão os efeitos mais prováveis de processo da integração das Américas sob o ponto de vista econômico? E qual será o impacto do aprofundamento do Mercosul?

Este artigo procura responder estas questões através do modelo de equilíbrio geral computável Global Trade Analysis Project (GTAP), que adota uma estrutura de mercado de competição perfeita e retornos constantes de escala, para analisar as alterações no bem-estar e no padrão de comércio causadas pela formação da ALCA e pela consolidação do Mercosul sobre os países membros e não membros dos blocos. O artigo é organizado da seguinte forma: a próxima seção apresenta a agregação setorial e regional escolhida para as

3 Lawrence (1997) e Ethier (1998) fornecem uma resenha das principais características de cada onda de regionalismo. 
simulações bem como as tarifas de importação vigentes no equilíbrio inicial da economia em 1995. Os detalhes dos experimentos, com ênfase na direção e na magnitude das mudanças tarifárias como resultado das simulações são discutidos na seção três. A seção quatro apresenta os resultados realçando as consequências da integração regional sobre o padrão de comércio, produção e bem-estar. A última seção conclui.

\section{Agregação e as tarifas no equilíbrio inicial}

As 45 regiões e 50 mercadorias da versão 4 da base de dados do GTAP foram agrupadas em 10 regiões e 10 setores de forma a permitir a mensuração dos efeitos sobre o comércio e bem-estar do Brasil e de seus principais parceiros comerciais e dos principais produtos comercializados dentro e fora da ALCA. A tabela 1 mostra a agregação regional e setorial usada nos experimentos. A agregação regional inclui os países do NAFTA (Estados Unidos, Canadá, México), os membros do Mercosul exceto Paraguai (Argentina, Brasil, Uruguai), ${ }^{4}$ o Resto da América do Sul (Chile, Colômbia, Venezuela, Peru, Equador e Bolívia), a União Europeia, a ASEAN (Indonésia, Malásia, Filipinas, Singapura, Tailândia e Japão) e o Resto do Mundo. O critério para estabelecer esta agregação privilegiou os países do hemisfério e aquelas regiões com os maiores laços comerciais com o Brasil. Desta forma, apenas em torno de 22\% do comércio do Brasil é feito com a região Resto do Mundo em 1995. Os 50 setores da versão 4 da base de dados do GTAP foram reunidos em 10 setores agregados: grãos, outros produtos agrícolas, pecuária, extração mineral, alimentos processados, vestuário, equipamento de transporte, máquinas, outras manufaturas e serviços. Eles foram selecionados tendo em mente a conveniência de desagregar tanto setores agrícolas como industriais importantes para a pauta comercial brasileira.

Antes de partir para os experimentos em si vale a pena examinar a estrutura de proteção presente nas simulações adotadas neste projeto. As tarifas bilaterais ao nível de agregação apresentada pelo GTAP (50 setores na versão 4) são obtidas pela agregação das tarifas não discriminatórias a seis ou oito dígitos do Sistema Harmonizado (HS), utilizando como ponderação o valor das importações bilaterais. ${ }^{5}$ Assim, o modelo fornece tarifas bilaterais que refletem diferenças na composição das tarifas e do comércio em 1995. Valores positivos representam uma tarifa de importação, enquanto valores negativos representam um subsídio às importações. Utilizando como exemplo o modelo a ser usado neste projeto, cada um dos 10 países apresenta nove tarifas de importação diferentes para cada um dos 10 setores (pois um país não pode importar dele mesmo).

4 O Paraguai, o menor membro do Mercosul em termos de PIB e comércio, é o único país do bloco que não é analisado separadamente pelas simulações, dado que esta versão da base de dados do GTAP ainda não disponibiliza sobre o país separadamente.

5 A concordância entre estas duas classificações pode ser obtida no site do GTAP: <http://www.gtap.agecon. purdue.edu/>. 
TABELA 1. AGREGAÇÃO REGIONAL E SETORIAL

\begin{tabular}{l|l}
\hline Agregação Regional & Agregação Setorial \\
\hline 1. Argentina (Arg) & 1. Grãos \\
2. Brasil (Bra) & Arroz, trigo, grãos de cereais. \\
3. Uruguai (Ury) & 2. Outros Produtos Agrícolas (Out. Agrícolas) \\
4. Estados Unidos (EUA) & Vegetais, frutas, nozes, sementes oleaginosas, cana-de-açúcar, açúcar de \\
5. Canadá (Can) & beterraba, fibras de plantas. \\
6. México & 3. Pecuária \\
7. Resto da América do Sul (RAS) & Gado bovino, ovelha e cabras, cavalos, produtos animais, leite, lã, seda. \\
8. União Européia (UE) & \\
9. Asean + Japão (Asean) & 4. Recursos Naturais, Extrativa (Rec. Naturais) \\
1o. Resto do Mundo (RoW) & Silvicultura, pesca, carvão, óleo, gás, minerais, petróleo, produtos do carvão. \\
& 5. Alimentos Processados (Alimentos) \\
& Produtos de carne bovina, outras carnes, óleos e gordura vegetal, Laticínios, \\
& arroz processado, açúcar, outros alimentos, bebidas e tabaco. \\
& 6. Vestuário \\
& Têxteis e vestuário. \\
& 7. Equipamento de Transporte (Equip. Transp.) \\
& Veículos automotores e autopeças. \\
8. Máquinas & Equipamentos eletrônicos, outras máquinas e equipamentos. \\
9. Outras Manufaturas (Out. Manuf.) & Produtos de couro, produtos de lã, produtos de papel, publicações, químicos, \\
borracha, produtos plásticos, produtos minerais, metais ferrosos, outros \\
metais. \\
1o. Serviços \\
Eletricidade, manufatura do gás, distribuição, água, construção, comércio, \\
transporte, serviços financeiros, negócios, serviços recreacionais, administra- \\
ção pública e defesa, educação, saúde, aluguéis.
\end{tabular}

FONTE: Base de dados GTAP versão 4, McDougall et al. (1998).

Entretanto, um problema teve que ser resolvido inicialmente. Embora a base de dados da versão 4 do GTAP já elimine tanto as tarifas de importação como os subsídios para os países que pertençam a um mesmo bloco comercial, esta versão só reconhece quatro blocos comerciais em 1995, não incluindo o Mercosul. ${ }^{6}$ Assim, na base de dados do GTAP todos os setores apresentam ou uma tarifa ou um subsídio no comércio intra-Mercosul. Desta forma, enquanto os dados relativos ao comércio refletem as preferências, os dados da política comercial (tarifas + subsídios) não refletem a realidade. Como resultado, é necessário, antes de proceder às simulações, fazer com que estes dados sejam consistentes. Para ajustar os dados de tarifas e subsídios, eliminando todas as restrições e os incentivos no comércio intrabloco e mantendo inalteradas

6 Os blocos comerciais reconhecidos pela versão 4 do GTAP são a União Européia, o NAFTA, o tratado entre a União Européia e a Área de Livre Comércio da Europa e o tratado entre Austrália e Nova Zelândia (Anzcerta na sigla em inglês). 
as tarifas extrabloco, será utilizada a simulação denominada Altertax. ${ }^{7}$ As tarifas de todos os demais países ou regiões permanecerão inalteradas. Este ajustamento representará o equilíbrio inicial em 1995 em ambas as simulações realizadas neste artigo.

\section{Os experimentos}

Duas simulações são realizadas. A primeira é denominada ALCA, e trata dos efeitos econômicos sobre os países membros e não membros da ALCA provocada pelas mudanças nas tarifas de importação entre 1995 (equilíbrio inicial da base de dados da versão 4 do GTAP) e 2016 (ano da liberalização plena do comércio intrabloco), considerando-se a plena liberalização tarifária intra-ALCA. Partindo-se do equilíbrio inicial em 1995, as tarifas de importação existentes entre os países da ALCA são eliminadas, mantendo-se inalteradas as tarifas de importação em relação aos países e/ou regiões não membros do bloco vigentes em 1995 .

TABELA 2. VARIAÇÃO DAS TARIFAS SIMPLES DE IMPORTAÇÃO NA SIMULAÇÃO ALCA (\%)

\begin{tabular}{l|c|c|c|c|c|c|c}
\hline Setores & Arg & Bra & Ury & RAS & EUA & Canadá & México \\
\hline Grãos & 6.92 & 0.74 & 0.40 & 15.72 & -0.19 & -0.24 & 1.28 \\
Out.Agrícolas & -4.20 & -4.60 & -6.61 & -15.39 & -17.86 & -0.48 & 1.85 \\
Pecuária & -1.45 & -4.53 & -5.91 & -11.23 & -2.64 & -0.07 & 0.21 \\
Rec.Naturais & -4.42 & -9.36 & 0.00 & -10.68 & -0.55 & -1.42 & -5.01 \\
Alimentos & -13.06 & -5.75 & -5.65 & -15.63 & -10.97 & -4.19 & 0.85 \\
Vestuário & -14.89 & -10.11 & -14.17 & -17.74 & -9.62 & -10.29 & -11.60 \\
Equip.Transp. & -13.70 & -21.57 & -4.12 & -18.85 & -0.76 & -5.52 & -9.41 \\
Máquinas & -7.62 & -16.29 & -1.81 & -13.73 & -1.01 & -1.04 & -9.82 \\
Out. Manuf. & -9.01 & -6.82 & -9.11 & -14.00 & -1.63 & -3.44 & -8.74 \\
\hline
\end{tabular}

FONTE: Base de dados GTAP versão 4, McDougall et al. (1998).

A tabela 2 mostra a redução tarifária intrabloco média para cada país da ALCA. Os choques positivos nas tarifas de alguns setores, especialmente grãos, refletem a existência de subsídios, como mencionado anteriormente. Nos países do Mercosul ocorre a maior queda tarifária nos setores de material de transporte, vestuário e máquinas, refletindo as tarifas mais altas vigentes nestes setores em 1995. No Brasil, a maior queda se verificou no setor de

7 A simulação Altertax é um procedimento para melhorar a qualidade dos dados no equilíbrio inicial sempre que informações mais precisas estiverem disponíveis. Ela usa uma closure e um arquivo de parâmetros especiais para garantir que as mudanças nas tarifas alterem o mínimo possível as outras variáveis do modelo. Ela funciona como outra simulação qualquer, na qual as tarifas são alteradas e o GTAP calcula as mudanças nos demais fluxos do modelo. De acordo com Malcolm (1998), a diferença entre um experimento convencional e o Altertax é que no primeiro a estrutura do modelo e o valor dos parâmetros são escolhidos de modo a representar a realidade econômica de forma mais acurada possível, enquanto no caso do Altertax eles são escolhidos para minimizar as mudanças na base de dados. 
material de transporte, chegando a 21,6\%, enquanto na Argentina a maior redução foi de 14,9\% no setor de vestuário. Nos países do NAFTA a queda mais acentuada ocorreu em outros produtos agrícolas nos Estados Unidos (17,9\%) e vestuário no Canadá (10,3\%) e México (11,6\%).

A segunda simulação, denominada MERC, avalia os efeitos da plena implementação da tarifa externa comum (TEC) do Mercosul, originalmente prevista para 2006. Assim, aqueles países que fazem parte do Mercosul têm as suas tarifas de importação extrabloco ajustadas para aqueles valores determinados para 2006, desconsiderando-se a formação da ALCA. Como na simulação anterior, no equilíbrio inicial já haveria livre comércio entre os países do Mercosul, sendo observado apenas o impacto que a convergência à TEC teria sobre os membros e não membros do Mercosul. O valor assumido pela TEC do Mercosul foi calculado a partir de dados de tarifas do Sistema Harmonizado a seis dígitos, que foram agregados inicialmente aos 50 setores do GTAP e, logo após, foram calculadas as tarifas médias simples para cada um dos 10 setores utilizados nas simulações. ${ }^{8}$

A tabela 3 mostra a variação tarifária para atingir a TEC em 2006, bem como o seu valor. O Brasil é o país que apresenta as maiores variações, tanto ascendentes como descendentes, para convergir a TEC. Os setores de equipamento de transporte e máquinas mostram uma acentuada convergência declinante à TEC, enquanto há uma forte elevação das tarifas nos setores de grãos, alimentos e vestuário. Argentina e Uruguai, por sua vez, apresentam variações menos expressivas do que as observadas no Brasil. O Uruguai é o país que mais frequentemente tem que elevar suas tarifas para ajustá-las à TEC do Mercosul, mostrando seu menor protecionismo em 1995. A estrutura da TEC concede um grau maior de proteção à indústria, especialmente vestuário, equipamentos de transporte e máquinas, enquanto os setores agrícolas exibem tarifas de apenas um dígito.

TABELA 3. VARIAÇÃO DAS TARIFAS PARA ATINGIR A TEC DO MERCOSUL EM $2006(\%)$

\begin{tabular}{lcc|c|c}
\hline Setores & Arg & Bra & Ury & TEC \\
\hline Grãos & 10,05 & 15,98 & 4,25 & $5 \cdot 40$ \\
Out.Agrícolas & 2,40 & 1,02 & 0,37 & $7 \cdot 32$ \\
Pecuária & 2,02 & 0,61 & $-0,66$ & 4.99 \\
Rec.Naturais & $-2,12$ & $-5,50$ & 2,77 & 3.87 \\
Alimentos & $-1,63$ & 8,93 & 4,05 & 12.26 \\
Vestuário & $-0,29$ & 3,53 & 0,02 & 17.56 \\
Equip.Transp. & $-1,71$ & $-10,05$ & 7,08 & 14.67 \\
Máquinas & 4,49 & $-5,39$ & 7,68 & 12.86 \\
Out. Manuf. & $-1,04$ & 0,91 & 0,18 & 9.67 \\
\hline
\end{tabular}

FONTE: Base de dados GTAP versão 4, McDougall et al. (1998). 
Os modelos de equilíbrio geral computáveis têm sido amplamente empregados para avaliar o impacto dos Acordos Preferenciais de Comércio (APC) sobre os países membros e não membros. Eles permitem estimar as mudanças de bem-estar associadas com reduções preferenciais da estrutura de proteção, cobrindo tanto os efeitos estáticos como os efeitos dinâmicos da integração. Ganhos estáticos surgem da especialização da produção de acordo com as vantagens comparativas, alterações nos termos de troca, aumento de eficiência devido à maior competição externa e economias de escala. Os efeitos dinâmicos se referem às mudanças nas taxas de crescimento econômico. Baldwin e Venables (1995) dividem a análise baseada em modelos de equilíbrio geral computável em três gerações conforme seus efeitos. A primeira fase se baseia em uma estrutura de mercado onde prevalece a competição perfeita em que ganhos dinâmicos não são considerados. Nestes modelos somente ganhos estáticos associados com uma melhor alocação de recursos e melhorias nos termos de troca têm lugar. A segunda fase compreende avaliações baseadas em modelos de competição imperfeita em que economias de escala e diferenciação de produto apresentam um papel relevante em determinados setores industriais. A terceira fase introduz os efeitos da integração nos níveis de poupança, investimento e crescimento econômico.

Um aspecto interessante é o aparente trade-off entre a magnitude dos resultados empíricos obtidos através das abordagens baseadas nas diferentes fases e o grau de confiança no entendimento destes diferentes efeitos (por exemplo, Allen et al. 1996; Hoekman et al. 1998). De um lado, a magnitude dos resultados das abordagens baseadas em economias de escala, competição e crescimento econômico, é maior do que aquela obtida pelos modelos baseados na eficiência estática e mudanças nos termos de troca. ${ }^{9}$ De outro lado, os modelos com competição perfeita envolvem mudanças de políticas de magnitude conhecida e métodos analíticos robustos, enquanto as abordagens da segunda e terceira gerações envolvem inferências a partir de uma estrutura teórica com muitas controvérsias em relação a temas como a extensão das economias de escala e a estimação das margens de mark-up em mercados com competição imperfeita. ${ }^{10}$

Assim, este artigo emprega o modelo de equilíbrio geral aplicado Global Trade Analysis Project (GTAP), que adota uma estrutura de mercado de competição perfeita e retornos constantes de escala, para analisar as alterações no bem-estar

9 A literatura que trata de modelos de equilíbrio geral computáveis mostra que os ganhos de bem-estar são usualmente maiores em modelos com competição imperfeita quando comparado com modelos que só permitem competição perfeita em estudos analisando o NAFTA (por exemplo, Roland-Horst et al. 1992; Brown et al. 1992); a União Europeia (por exemplo, Harrison et al., 1994; Haaland \& Norman 1992) e o Mercosul (por exemplo, Flores 1997; Cavalcante \& Mercenier 1999), dado com que eles criam mecanismos adicionais através dos quais um APC pode afetar o bem-estar. Entretanto, a teoria não afirma que os ganhos tenham que ser necessariamente maiores em uma estrutura de mercado marcada pela competição imperfeita tampouco que eles variam na mesma direção.

10 Harrison et al. (1997), por exemplo, salientam que estes ganhos adicionais estão mais associados com mark-ups mais elevados e/ou com a incorporação de outras mudanças, como elasticidades, do que com a mudança do regime em si. 
e no padrão de comércio tanto nos países membros dos blocos como no resto do mundo causadas pela formação da ALCA e do Mercosul. ${ }^{11}$ Por fim, cabe salientar que a ênfase dada aos efeitos das simulações sobre o bem-estar dos países envolvidos na análise dos resultados se justifica pela importância que esta variável tem sobre a população, o que muitas vezes é ignorado pelos estudos que tratam do tema, que se concentram apenas nos efeitos sobre PIB e comércio exterior. Como salienta Sapir (1992: 1497):

As Waelbroeck (1976) correctly warned, not too much interest should attach to the effects of economic integration on trade. The latter is an "irrelevant variable", interesting simply because of its impact on the primary objectives of economic policy, welfare and income distribution."

Em resumo, a avaliação dos efeitos da consolidação do Mercosul e da formação da ALCA é realizada supondo o seguinte cenário:

- $\quad$ Uma simulação prévia que eliminou a incidência de tarifas de importação entre os membros do Mercosul que constava da base de dados da versão 4 do GTAP (através do procedimento Altertax), tendo como base de dados o ano de 1995, servindo de equilíbrio inicial para ambas as simulações;

- $\quad$ Não inclui a eliminação de barreiras não tarifárias; ${ }^{12}$

- $\quad$ Análise dos efeitos estáticos da integração, que se referem aos impactos alocativos e de termos de troca, no que se convencionou chamar de 1a geração dos modelos de equilíbrio geral computáveis, com ênfase nos efeitos sobre o bem-estar dos países envolvidos.

\section{Resultados}

\subsection{A formação da ALCA}

Nesta seção são apresentados os efeitos potenciais sobre produção, fluxos de comércio exterior e bem-estar causados pela formação da ALCA, através da plena liberalização tarifária intrabloco, dando-se ênfase especial para o caso brasileiro. De acordo com a tabela 4, a produção doméstica brasileira se expande na maior parte dos setores primários (grãos, outros produtos agrícolas e pecuária) e naqueles setores industriais tradicionais (alimentos e vestuário). Em compensação, os setores de máquinas e equipamentos de 
transporte experimentam uma expressiva variação negativa, refletindo a maior liberalização tarifária ocorrida nestes setores. O setor de máquinas brasileiro apresenta a maior queda entre todos os países da ALCA analisados, chegando a 3,42\%. O padrão da variação da produção doméstica Argentina é semelhante ao brasileiro, com queda na maioria dos setores industriais e aumento da produção dos setores primários. Canadá e Estados Unidos apresentam um quadro oposto, com a produção doméstica dos setores industriais crescendo enquanto declina a produção dos setores primários. Chama a atenção o crescimento da produção de equipamentos de transporte em todos os países que fazem parte do NAFTA, em especial no México onde ele alcança uma expansão de 6,99\%.

\section{TABELA 4. VARIAÇÃO DA PRODUÇÃO DOMÉSTICA}

\begin{tabular}{l|c|c|c|c|c|c|c}
\hline Setores & Arg & Bra & Ury & EUA & Canadá & México & UE \\
\hline Grãos & $-1,04 \%$ & $0,33 \%$ & $-0,37 \%$ & $-0,28 \%$ & $-1,47 \%$ & $0,08 \%$ & $0,07 \%$ \\
Out.Agrícolas & $1,27 \%$ & $0,94 \%$ & $1,59 \%$ & $-0,65 \%$ & $-0,44 \%$ & $-0,28 \%$ & $-0,06 \%$ \\
Pecuária & $0,57 \%$ & $0,49 \%$ & $0,31 \%$ & $-0,13 \%$ & $0,47 \%$ & $0,19 \%$ & $-0,06 \%$ \\
Rec.Naturais & $0,98 \%$ & $-0,31 \%$ & $-0,18 \%$ & $-0,11 \%$ & $-0,09 \%$ & $-0,56 \%$ & $0,00 \%$ \\
Alimentos & $0,81 \%$ & $0,66 \%$ & $-0,27 \%$ & $-0,13 \%$ & $0,45 \%$ & $0,46 \%$ & $-0,08 \%$ \\
Vestuário & $-0,41 \%$ & $1,00 \%$ & $3,83 \%$ & $-0,16 \%$ & $-0,39 \%$ & $-0,86 \%$ & $-0,03 \%$ \\
Equip.Transp. & $-3,51 \%$ & $-2,79 \%$ & $-14,15 \%$ & $0,50 \%$ & $1,27 \%$ & $6,99 \%$ & $-0,18 \%$ \\
Máquinas & $-1,28 \%$ & $-3,42 \%$ & $-3,36 \%$ & $0,29 \%$ & $0,15 \%$ & $-1,36 \%$ & $-0,04 \%$ \\
Out. Manuf. & $-0,13 \%$ & $0,43 \%$ & $-0,41 \%$ & $0,04 \%$ & $-0,17 \%$ & $-0,17 \%$ & $-0,03 \%$ \\
Serviços & $-0,03 \%$ & $0,01 \%$ & $0,05 \%$ & $-0,03 \%$ & $-0,02 \%$ & $-0,02 \%$ & $0,02 \%$ \\
\hline
\end{tabular}

FONTE: Simulação ALCA do GTAP.

A tabela 5 mostra a variação das importações brasileiras provenientes tanto dos parceiros da ALCA como do resto do mundo. Em todos os setores há um nítido deslocamento das importações dos países não membros para os sócios da ALCA, caracterizando o que se convencionou chamar de desvio de comércio em todos os setores examinados. ${ }^{13}$ Naqueles setores onde houve a maior redução tarifária, equipamento de transporte e máquinas, o desvio de comércio ocorreu de forma mais intensa, com as importações dos países membros do bloco crescendo 151,4\% e 80,7\%, respectivamente, com quedas acentuadas das importações provenientes de países não membros. As importações totais intrabloco cresceram 44,5\%, enquanto as provenientes de fora do bloco declinaram em 17,0\%. O acentuado crescimento das importações intrabloco levou à expansão das importações totais do Brasil em todos os setores, à exceção de serviços, fazendo as importações totais crescerem 8,8\%. ${ }^{14}$

13 Viner (1950) introduziu os conceitos de criação e desvio de comércio. Criação de comércio ocorre quando as importações de um parceiro do bloco substituem a produção doméstica menos eficiente quando as preferências tarifárias são introduzidas. O desvio de comércio resulta da substituição das importações de um país mais eficiente de fora do bloco pelas importações de parceiros do bloco quando o bloco é formado.

14 Vale ressaltar que os únicos países da ALCA que sofreram perda de sua participação no mercado brasileiro foram Argentina e Uruguai, pois estes já detinham 100\% de preferências ao nível do Mercosul em 1995. 
TABELA 5. VARIAÇÃO NO VOLUME DAS IMPORTAÇÕES BRASILEIRAS

\begin{tabular}{lcc|c}
\hline \multicolumn{1}{c}{ Setores } & IntraBloco & ExtraBloco & Total \\
\hline Grãos & $3,7 \%$ & $-2,9 \%$ & $3,2 \%$ \\
Out.Agrícolas & $12,6 \%$ & $-6,1 \%$ & $4,6 \%$ \\
Pecuária & $3,6 \%$ & $-1,5 \%$ & $2,2 \%$ \\
Rec.Naturais & $29,8 \%$ & $-11,9 \%$ & $4,4 \%$ \\
Alimentos & $5,5 \%$ & $-3,9 \%$ & $0,9 \%$ \\
Vestuário & $28,9 \%$ & $-9,6 \%$ & $5,8 \%$ \\
Equip.Transp. & $151,4 \%$ & $-47,4 \%$ & $31,2 \%$ \\
Máquinas & $80,7 \%$ & $-27,8 \%$ & $14,5 \%$ \\
Out. Manuf. & $24,3 \%$ & $-11,0 \%$ & $5,7 \%$ \\
Serviços & $-2,4 \%$ & $-1,3 \%$ & $-1,6 \%$ \\
Total & $44,5 \%$ & $-17,0 \%$ & $8,8 \%$ \\
\hline
\end{tabular}

FONTE: Simulação ALCA do GTAP.

A tabela 6 mostra a evolução das exportações brasileiras. Assim como o ocorrido nas importações, a liberalização preferencial proporcionou um forte incremento das exportações do país para os demais parceiros do bloco. Em vários setores a expansão das exportações para os demais parceiros da ALCA supera 50\%, como vestuário (52,9\%), outros produtos agrícolas $(54,5 \%)$ e equipamento de transporte $(52,5 \%)$. O aumento do volume total das exportações chegou a 13,5\%, superando o crescimento das importações totais, embora o volume das exportações intrabloco tenha crescido a uma taxa inferior àquela observada nas importações dos demais parceiros da ALCA. O maior dinamismo das exportações brasileiras totais em relação às importações totais se explica pela inexistência do que se convencionou chamar de desvio de exportações, pois também houve um aumento das exportações para os países não membros do bloco ao lado do incremento das exportações intrabloco. ${ }^{15} \mathrm{O}$ setor que apresentou a maior expansão das exportações totais foi o de material de transporte, que ampliou suas vendas totais em 41,5\%, seguido pelo setor de vestuário, que registrou crescimento das exportações totais de 35,2\%. Isto se explica, em parte, pela incidência de tarifas mais elevadas nestes setores nos principais países da ALCA antes da liberalização comercial.

TABELA 6. VARIAÇÃO NO VOLUME DAS EXPORTAÇÕES BRASILEIRAS

\begin{tabular}{lcc|c}
\hline Setores & IntraBloco & ExtraBloco & Total \\
\hline Grãos & $50,0 \%$ & $0,0 \%$ & $22,2 \%$ \\
Out.Agrícolas & $54,5 \%$ & $0,9 \%$ & $11,2 \%$ \\
Pecuária & $11,1 \%$ & $0,7 \%$ & $2,4 \%$ \\
Rec.Naturais & $4,2 \%$ & $5,0 \%$ & $4,9 \%$ \\
Alimentos & $43,6 \%$ & $2,7 \%$ & $8,3 \%$ \\
Vestuário & $52,9 \%$ & $5,1 \%$ & $35,2 \%$ \\
Equip.Transp. & $52,5 \%$ & $22,5 \%$ & $41,5 \%$ \\
Máquinas & $19,9 \%$ & $8,9 \%$ & $16,4 \%$ \\
Out. Manuf. & $21,6 \%$ & $5,0 \%$ & $13,0 \%$ \\
Serviços & $3,2 \%$ & $3,1 \%$ & $3,1 \%$ \\
Total & $26,8 \%$ & $4,7 \%$ & $13,5 \%$ \\
\hline
\end{tabular}

FONTE: Simulação ALCA do GTAP.

15 O termo "desvio de exportações" foi cunhado originalmente por Winters (1997) e se refere a um aumento das exportações intrabloco em detrimento das exportações extrabloco em função da formação de um bloco regional, com efeitos negativos sobre o bem-estar dos países não membros. 
Em modelos de equilíbrio geral estáticos, com dotação de fatores e tecnologia fixas, a forma de incrementar o bem-estar ocorre através da redução das distorções existentes com as mudanças na eficiência alocativa resultantes da interação entre as mudanças nas tarifas e quantidades ${ }^{16}$ Entretanto, as mudanças no bem-estar não se restringem às mudanças alocativas, mas também incluem as mudanças nos termos de troca e no preço relativo da poupança e investimento. ${ }^{17} \mathrm{O}$ impacto sobre o bem-estar derivado do componente investimento-poupança (I-S) depende do preço da poupança e do investimento e do fato da região ser uma supridora ou recebedora líquida de poupança. ${ }^{18}$ As regiões que são supridoras líquidas de poupança se beneficiam de um aumento no preço da poupança em relação ao preço do investimento, enquanto os recebedores líquidos perdem.

Os ganhos de eficiência estão estreitamente relacionados com o grau no qual um país reduz suas tarifas. Produtos importados mais baratos provocam ganhos tanto no consumo ampliado como na forma na qual os recursos domésticos são aplicados. A tabela 7 fornece a decomposição dos efeitos alocativos por setor para cada país e/ou região decorrentes da formação da ALCA. De forma não surpreendente, os resultados mostram que o Brasil, que reduziu suas tarifas de forma mais acentuada, especialmente nos setores industriais, é o país que mais se beneficia de ganhos alocativos nesta simulação, sendo responsável pela maior parte dos ganhos totais, US\$1.305 milhões frente a US\$ 1.878 milhões. O Brasil apresenta ganhos alocativos em quase todos os setores, sendo os setores de máquinas e outras manufaturas aqueles com ganhos mais expressivos. Somente o setor de máquinas foi responsável por quase um terço dos ganhos alocativos totais, chegando a US\$ 536 milhões. Os Estados Unidos, assim como os demais países do NAFTA, também experimentam ganhos alocativos (US\$ 405 milhões), concentrados especialmente nos mesmos setores que obtiveram ganhos significativos no Brasil. A Argentina, ao contrário, mostra uma pequena perda de bem-estar devido ao efeito alocativo, concentradas em equipamento de transporte e máquinas. A União Europeia, por sua vez, teve perdas que, embora pouco significativas, chegaram a US\$ 73 milhões.

16 A variação no equivalente da renda do consumidor regional (EV) reflete a diferença entre a despesa requerida para obter o novo nível de utilidade aos preços iniciais (YEV) e o nível de utilidade disponível no equilíbrio inicial (Y), ou seja, EV= YEV -Y.

17 Os termos de troca são definidos como a razão entre os preços recebidos pelos produtos comercializáveis e os preços pagos por eles.

18 A closure adotada nas simulações (NewMRGE), em que o preço da poupança varia entre as regiões, minimiza a diferença entre o preço do investimento e o da poupança, fazendo-os se moverem próximos um ao outro de forma a refletir o fato de que a maior parte da poupança é investida domesticamente. 
TABELA 7. DECOMPOSIÇÃO DA EFICIÊNCIA ALOCATIVA (1995 US\$ MILHÕES)

\begin{tabular}{l|c|c|c|c|c|c|c|c|c}
\hline & Arg & Bra & Ury & EUA & Canadá & México & UE & Asean & Total \\
\hline Grãos & -15 & -2 & 0 & 18 & 15 & 4 & -24 & -37 & -32 \\
Out.Agrícolas & 1 & 270 & 0 & 58 & 1 & 3 & 2 & -5 & 356 \\
Pecuária & 0 & 2 & 0 & 6 & -7 & -7 & 11 & 0 & 7 \\
Rec.Naturais & 1 & -2 & 0 & 15 & 2 & -2 & -4 & -4 & 38 \\
Alimentos & 5 & 104 & -2 & 35 & 1 & 11 & 41 & -5 & 266 \\
Vestuário & 4 & 18 & -7 & 54 & 7 & -4 & -10 & -8 & 30 \\
Equip.Transp. & -20 & 84 & 1 & 89 & 14 & 117 & -40 & -15 & 127 \\
Máquinas & -15 & 536 & -1 & 107 & 12 & -2 & -55 & 24 & 719 \\
Out. Manuf. & 4 & 297 & 0 & 108 & 15 & 17 & -36 & -14 & 399 \\
Serviços & 0 & -3 & -1 & -86 & 2 & -4 & 43 & 4 & -32 \\
Total & -35 & 1.305 & -9 & 405 & 62 & 135 & -73 & -59 & 1.878 \\
\hline
\end{tabular}

FONTE: Simulação ALCA do GTAP.

Entretanto, quando os termos de troca e da poupança-investimento são considerados o quadro se modifica bastante (tabela 8). O Brasil é o país da ALCA que apresenta a maior deterioração dos termos de troca, cancelando parcialmente os ganhos alocativos. Isto resulta principalmente na queda dos preços de exportação brasileiros para os demais países e/ou regiões do modelo. O significativo corte das tarifas de importação aumentou a demanda por importações de todas as regiões, como salientado anteriormente, criando dois efeitos. De um lado, criou a necessidade de elevar a oferta de exportações, para compensar o aumento das importações, levando a queda dos preços das exportações. Por outro lado, outros países, especialmente Estados Unidos e México, se beneficiaram da maior demanda por seus produtos elevando seus preços de exportação, gerando uma melhoria nos seus termos de troca. Esta possibilidade é aventada por Panagariya (1997), que ao analisar a formação do NAFTA sugere que sempre que um país com tarifas elevadas forma um bloco comercial com outro de tarifas baixas haveria uma transferência líquida da receita de tarifa do primeiro para os exportadores do último. ${ }^{19}$ Quando os ganhos agregados de bem-estar são ponderados pelo PIB de cada país e/ou região, México, Brasil e Estados Unidos nesta ordem são os maiores beneficiados pela formação do bloco, embora os ganhos sejam pouco significativos, chegando a apenas $0,17 \%$ do PIB no caso mexicano. O Uruguai registra a maior perda de bem-estar em relação ao PIB (o,04\%), enquanto a União Europeia apresentou a maior queda absoluta (U\$ 1.050 milhões), fortemente influenciada pela deterioração dos termos de troca verificada nesta região. 
TABELA 8. EFEITOS SOBRE O BEM-ESTAR (1995 US\$ MILHÕES)

\begin{tabular}{l|c|c|c|c|r}
\hline Regiões & Efeitos Alocativos & Termos de Troca & Efeito I-S & Efeito Agregado & \% do PIB \\
\hline Arg & -35 & -72 & -2 & -108 & $-0,042 \%$ \\
Bra & 1.305 & -631 & -176 & 497 & $0,070 \%$ \\
Uru & -9 & -2 & -4 & -14 & $-0,083 \%$ \\
EUA & 405 & 2.423 & 357 & 3.185 & $0,045 \%$ \\
Canadá & 62 & -31 & -41 & -9 & $-0,002 \%$ \\
México & 135 & 439 & -95 & 479 & $0,171 \%$ \\
RAS & 292 & -43 & -73 & 175 & $0,058 \%$ \\
UE & -73 & -1.050 & 32 & -1.091 & $-0,013 \%$ \\
Asean & -59 & -247 & 11 & -296 & $-0,005 \%$ \\
ROW & -144 & -798 & -10 & -952 & $-0,019 \%$ \\
Total & 1.878 & -10 & -1 & 1.866 & $0,007 \%$ \\
\hline
\end{tabular}

FONTE: Simulação ALCA do GTAP.

\subsection{O Impacto da TEC}

Como mencionado anteriormente, a plena implementação da união aduaneira no Mercosul só iria ocorrer em 2006. Inicialmente, as tarifas intrabloco foram removidas entre 1991 e 1994. No entanto, somente em 2006 as tarifas de cada membro do bloco irão convergir para a TEC. Entretanto, este prazo não foi cumprido, permanecendo inúmeras exceções à TEC. Esta seção procura estimar os efeitos potenciais da convergência à TEC sobre os integrantes do Mercosul, em especial o Brasil. A convergência ocorre em uma situação na qual já há livre comércio entre os integrantes do Mercosul e as tarifas extrabloco são aquelas vigentes em 1995 na base de dados do GTAP, correspondendo ao mesmo equilíbrio inicial da simulação anterior.

A convergência à TEC, como salientado na seção 3, causa uma elevação nas tarifas extrabloco em boa parte dos setores para Argentina e Uruguai, sendo que neste último há uma alta de tarifas quase generalizada, com as maiores elevações ocorrendo nos setores de equipamento de transporte e máquinas. O Brasil, por sua vez, embora também registre um aumento das tarifas em alguns setores, se caracteriza por uma acentuada convergência para baixo, ou seja, há uma tendência de queda das tarifas de importação para ajustarem-se à TEC, nos setores de equipamento de transporte e máquinas. Em razão disto, estes dois setores apresentam a maior queda do volume de produção doméstica no Brasil, atingindo 4,77\% no primeiro. No caso brasileiro, tanto a formação da ALCA como o aprofundamento do Mercosul têm um efeito similar sobre a produção doméstica, beneficiando os setores agrícolas e industriais mais tradicionais em detrimento dos setores industriais mais intensivos em capital. Como esperado, os países não pertencentes ao Mercosul tiveram variações no 
volume de produção pouco significativas, especialmente quando comparados à simulação anterior. União Europeia, Asean e o resto do mundo apresentam um melhor desempenho do que na simulação anterior, pois a convergência à TEC pelos países do Mercosul não teve um caráter discriminatório e, assim, estas regiões puderam competir em condições mais favoráveis com as demais regiões do modelo, especialmente com os países do NAFTA.

\section{TABELA 9. VARIAÇÃO DA PRODUÇÃO DOMÉSTICA}

\begin{tabular}{l|c|c|c|c|c|c|c}
\hline Setores & Arg & Bra & Ury & EUA & Canadá & México & UE \\
\hline Grãos & $0,57 \%$ & $0,78 \%$ & $0,56 \%$ & $-0,03 \%$ & $0,23 \%$ & $-0,02 \%$ & $-0,11 \%$ \\
Out.Agrícolas & $0,23 \%$ & $0,61 \%$ & $0,00 \%$ & $-0,03 \%$ & $-0,07 \%$ & $-0,08 \%$ & $-0,08 \%$ \\
Pecuária & $0,38 \%$ & $0,59 \%$ & $0,12 \%$ & $-0,02 \%$ & $-0,04 \%$ & $-0,01 \%$ & $-0,07 \%$ \\
Rec.Naturais & $-1,24 \%$ & $-1,99 \%$ & $-0,92 \%$ & $-0,02 \%$ & $0,00 \%$ & $-0,05 \%$ & $0,00 \%$ \\
Alimentos & $0,43 \%$ & $0,75 \%$ & $1,00 \%$ & $-0,02 \%$ & $-0,03 \%$ & $0,00 \%$ & $-0,08 \%$ \\
Vestuário & $0,12 \%$ & $0,61 \%$ & $-0,65 \%$ & $-0,04 \%$ & $0,04 \%$ & $-0,19 \%$ & $0,00 \%$ \\
Equip.Transp. & $-4,03 \%$ & $-4,77 \%$ & $-16,72 \%$ & $-0,02 \%$ & $0,12 \%$ & $0,90 \%$ & $0,17 \%$ \\
Máquinas & $1,47 \%$ & $-1,96 \%$ & $3,36 \%$ & $0,05 \%$ & $0,09 \%$ & $-0,08 \%$ & $0,02 \%$ \\
Out. Manuf. & $0,05 \%$ & $0,52 \%$ & $-0,49 \%$ & $-0,01 \%$ & $-0,07 \%$ & $-0,04 \%$ & $-0,02 \%$ \\
Serviços & $0,05 \%$ & $0,03 \%$ & $0,05 \%$ & $0,00 \%$ & $0,00 \%$ & $0,00 \%$ & $0,00 \%$ \\
\hline
\end{tabular}

FONTE: Simulação MERC do GTAP.

As importações totais brasileiras sofreram um pequeno acréscimo de 3,5\%, sendo alavancadas pelo desempenho das importações de fora do Mercosul, que cresceram 5,3\%, enquanto as importações intrabloco declinaram em 11,0\%, afastando os temores de desvio de comércio. O aumento das importações de fora do bloco foi puxado pelo desempenho do setor de equipamento de transporte, o qual o Brasil teve de reduzir a tarifa de importação de forma mais expressiva, geralmente chegando a dois dígitos. Neste setor verifica-se com mais intensidade a redução das importações intrabloco em benefício das importações extrabloco, caracterizando-se como um caso oposto ao de desvio de comércio, denominado na literatura de desvio de comércio interno. ${ }^{20}$ Entretanto, em alguns setores onde houve elevação das tarifas para convergência à TEC, as importações intrabloco aumentaram em detrimento das importações de fora do bloco, caso dos setores de alimentos e vestuário, caracterizando a situação clássica de desvio de comércio. 
TABELA 10. VARIAÇÃO NO VOLUME DAS IMPORTAÇÕES BRASILEIRAS

\begin{tabular}{lcc|c}
\hline \multicolumn{1}{c}{ Setores } & IntraBloco & ExtraBloco & Total \\
\hline Grãos & $0,7 \%$ & $-6,8 \%$ & $-1,6 \%$ \\
Out.Agrícolas & $-1,4 \%$ & $0,6 \%$ & $0,1 \%$ \\
Pecuária & $-1,8 \%$ & $-4,2 \%$ & $-3,0 \%$ \\
Rec.Naturais & $-24,5 \%$ & $17,1 \%$ & $11,9 \%$ \\
Alimentos & $11,9 \%$ & $-28,6 \%$ & $-13,7 \%$ \\
Vestuário & $6,9 \%$ & $-10,3 \%$ & $-7,0 \%$ \\
Equip.Transp. & $-44,5 \%$ & $37,6 \%$ & $21,2 \%$ \\
Máquinas & $-21,0 \%$ & $8,8 \%$ & $7,5 \%$ \\
Out. Manuf. & $0,8 \%$ & $-3,4 \%$ & $-3,0 \%$ \\
Serviços & $0,6 \%$ & $-2,2 \%$ & $-2,1 \%$ \\
Total & $-11,0 \%$ & $5,3 \%$ & $3,5 \%$ \\
\hline
\end{tabular}

FONTE: Simulação MERC do GTAP.

Já as exportações brasileiras para os parceiros do Mercosul não apenas cresceram como superaram a expansão das exportações para os países não membros do bloco, chegando a $8,3 \%$. Isto se deve ao aumento do protecionismo dos demais parceiros do bloco em relação aos países não membros. Como salientado anteriormente, Argentina e Uruguai, especialmente o último, tiveram que elevar boa parte de suas tarifas para convergir à TEC, favorecendo as exportações brasileiras em detrimento do resto do mundo. Isto ocorreu com mais intensidade nos setores de equipamento de transporte e máquinas, aqueles em que a elevação das tarifas nestes países ocorreu de forma mais intensa. Vale ressaltar que não houve queda do volume das exportações brasileiras para fora do Mercosul em nenhum dos setores examinados, dizimando o receio de desvio de exportação. Destaca-se mais uma vez o desempenho do setor de equipamento de transporte, o qual registrou a maior variação positiva, atingindo $23 \%$.

TABELA 11. VARIAÇÃO NO VOLUME DAS EXPORTAÇÕES BRASILEIRAS

\begin{tabular}{lcc|c}
\hline \multicolumn{1}{c}{ Setores } & IntraBloco & ExtraBloco & Total \\
\hline Grãos & $0,0 \%$ & $0,0 \%$ & $0,0 \%$ \\
Out.Agrícolas & $3,2 \%$ & $2,7 \%$ & $2,7 \%$ \\
Pecuária & $0,0 \%$ & $2,7 \%$ & $2,4 \%$ \\
Rec.Naturais & $-4,2 \%$ & $10,9 \%$ & $10,1 \%$ \\
Alimentos & $1,8 \%$ & $3,4 \%$ & $3,4 \%$ \\
Vestuário & $-0,4 \%$ & $5,7 \%$ & $4,5 \%$ \\
Equip.Transp. & $10,6 \%$ & $23,0 \%$ & $19,2 \%$ \\
Máquinas & $31,8 \%$ & $8,3 \%$ & $12,4 \%$ \\
Out. Manuf. & $1,2 \%$ & $5,7 \%$ & $5,2 \%$ \\
Serviços & $2,6 \%$ & $4,2 \%$ & $4,0 \%$ \\
Total & $8,3 \%$ & $6,4 \%$ & $6,6 \%$ \\
\hline
\end{tabular}

FONTE: Simulação MERC do GTAP. 
A análise da decomposição da eficiência alocativa mostra novamente o Brasil como o país que mais se beneficia com esta simulação, com os ganhos atingindo US\$1.101 milhões (tabela 12). Todos os setores que tiveram suas tarifas convergindo para baixo apresentaram ganhos alocativos, com ênfase nos já mencionados setores de material de transporte e máquinas. Já nos setores em que o nível de proteção aumentou houve perdas de eficiência alocativa, especialmente nos setores de alimentos e vestuário. Na Argentina, embora apenas o setor de máquinas tenha apresentado perda de eficiência, esta foi tão elevada que mais do que compensou o aumento de eficiência nos demais setores, levando a uma perda de eficiência total de US\$ 23 milhões para aquele país. O impacto total associado ao efeito alocativo chegou a US\$1.386 milhões, com a maior parte das regiões de fora do Mercosul se beneficiando de uma melhor alocação de recursos, ao contrário do ocorrido na simulação anterior.

TABELA 12. DECOMPOSIÇÃO DA EFICIÊNCIA ALOCATIVA (1995 US \$ MILHÕES)

\begin{tabular}{lcccccccccccc}
\hline & Arg & Bra & Ury & EUA & Canadá & México & UE & Asean & Total \\
\hline Grãos & 3 & -16 & 0 & 2 & -2 & 0 & 23 & 5 & 14 \\
Out.Agrícolas & 0 & 23 & 0 & 3 & 0 & 0 & 6 & -1 & 34 \\
Pecuária & 0 & -2 & 0 & 1 & 1 & 0 & 15 & 0 & 17 \\
Rec.Naturais & 13 & 192 & 0 & -8 & -1 & 0 & -1 & 1 & 229 \\
Alimentos & 3 & -108 & -1 & 3 & 1 & 0 & 113 & 3 & 38 \\
Vestuário & 0 & -50 & 2 & -2 & -1 & -2 & 0 & 0 & -54 \\
Equip.Transp. & 10 & 616 & -12 & -5 & 0 & 14 & 22 & 20 & 702 \\
Máquinas & -61 & 582 & -8 & 2 & 0 & 0 & 5 & -4 & 532 \\
Out. Manuf. & 10 & -132 & -5 & -2 & -3 & 1 & 3 & -1 & -132 \\
Serviços & 0 & -6 & 1 & -4 & 0 & 1 & 8 & 3 & 7 \\
Total & -23 & 1.101 & -24 & -11 & -5 & 14 & 195 & 25 & 1.386 \\
\hline
\end{tabular}

FONTE: Simulação MERC do GTAP.

Os resultados da mudança no bem-estar agregado para Brasil e Uruguai são positivos, chegando a $0,11 \%$ do PIB no último (tabela 13). No Brasil, mais uma vez a deterioração dos termos de troca não são suficientes para superar os ganhos alocativos, permitindo, assim, que o país tenha um ganho agregado de bem-estar da ordem de US\$ 254 milhões. Na Argentina a deterioração dos termos de troca reforça as perdas alocativas levando a uma perda total de bem-estar de US\$ 110 milhões. À exceção do Canadá, todas as regiões de fora do bloco se beneficiam com a simulação, especialmente o resto da América do Sul, com ganhos de bem-estar agregados equivalentes a 0,025\% do PIB da região. O ganho global de bem-estar chega a US\$ 1.381 milhões, ou $0,005 \%$ do PIB mundial. 
TABELA 13. EFEITOS SOBRE O BEM-ESTAR (1995 US\$ MILHÕES)

\begin{tabular}{lccccccc}
\hline Regiões & Efeitos Alocativos & Termos de Troca & Efeito I-S & Efeito Agregado & \% do PIB \\
\hline Arg & -23 & -87 & 0 & -110 & $-0,042 \%$ \\
Bra & 1.101 & -690 & -157 & 254 & $0,036 \%$ \\
Uru & -24 & 31 & 11 & 19 & $0,112 \%$ \\
EUA & -11 & -22 & 49 & 16 & $0,000 \%$ \\
Canadá & -5 & -29 & 4 & -30 & $-0,005 \%$ \\
México & 14 & 49 & -8 & 55 & $0,020 \%$ \\
RAS & 18 & 60 & -1 & 77 & $0,025 \%$ \\
UE & 195 & 183 & 26 & 403 & $0,005 \%$ \\
Asean & 25 & 117 & 37 & 179 & $0,003 \%$ \\
ROW & 97 & 384 & 37 & 518 & $0,010 \%$ \\
Total & 1.386 & -4 & -1 & 1.381 & $0,005 \%$ \\
\hline
\end{tabular}

FONTE: Simulação MERC do GTAP.

Após isolar os efeitos da formação da ALCA e da consolidação do Mercosul a partir da convergência à TEC do bloco é possível comparar os efeitos destas duas simulações sobre o bem-estar das regiões examinadas. A figura 1 mostra o impacto de ambas as simulações realizadas neste artigo sobre o bem-estar (relativo ao PIB de 1995 de cada país ou região). Para o Brasil o ganho de bem-estar agregado com a formação da ALCA seria praticamente o dobro daquele obtido com a consolidação do Mercosul (o,070\% do PIB contra 0,036\% do PIB). Para a Argentina, por sua vez, seria indiferente a formação de um ou de outro bloco no que tange aos efeitos sobre o bem-estar, pois em ambas as simulações as perdas seriam de 0,042\% do PIB. No caso da consolidação do Mercosul este é o país que registra a maior queda de bem-estar. O Uruguai é o país que apresenta os cenários mais antagônicos, com a maior queda de bem-estar devido à formação da ALCA (o,083\% do PIB) e o maior ganho de bem-estar em razão da consolidação do Mercosul (o,112\% do PIB) entre todas as regiões examinadas. O México é o país mais beneficiado com a formação da ALCA, com um ganho de bem-estar de 0,171\% do PIB, embora também apresente ganhos com a consolidação do Mercosul. Já os Estados Unidos não são afetados pelo Mercosul e é a quarta região mais beneficiada pela formação da ALCA. A União Europeia, ao contrário dos Estados Unidos, obtém uma situação mais privilegiada com o cenário Mercosul, com ganhos de bem-estar equivalentes a 0,005\% do PIB, enquanto apresenta uma perda de bem-estar de 0,013\% do PIB no cenário da ALCA. O resultado agregado para todas as regiões mostra que a formação da ALCA (0,007\% do PIB) gera ganhos de bem-estar ligeiramente superiores ao cenário da consolidação do Mercosul (0,005\% do PIB). 
FIGURA 1. SUMÁRIO DOS EFEITOS DAS SIMULAÇÕES SOBRE O BEM-ESTAR AGREGADO (\% DO PIB)

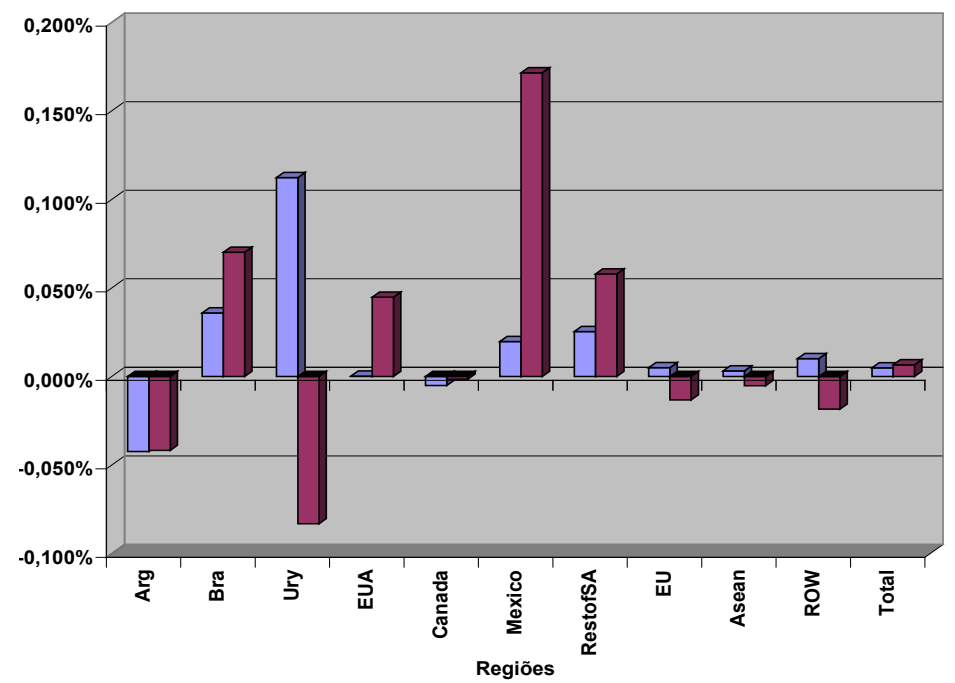

FONTE: Simulações ALCA e MERC do GTAP.

A magnitude dos resultados obtidos em ambas as simulações é pequena e, em grande parte, consequência da forma como elas foram conduzidas, baseadas na chamada primeira geração dos modelos de equilíbrio geral, em que prevalece uma estrutura de mercado de competição perfeita e os ganhos associados à escala, competição e variedade são ignorados, além de desconsiderar a remoção das barreiras não tarifárias. Modelos que incorporaram competição imperfeita permitindo que economias de escala e diferenciação de produto desempenhem um papel relevante em determinados setores industriais mostraram resultados mais animadores. Watanaki e Monteagudo (2001), por exemplo, que incorporam economias de escala e competição imperfeita em determinados setores, obtém resultados muito mais expressivos. ${ }^{21}$

Comparado com outros trabalhos na literatura que utiliza modelos de Equilíbrio Geral Computável, este artigo mostra que os resultados encontrados são qualitativamente similares, entretanto, com variações em termos de magnitude. Para a formação da ALCA, os ganhos em termos de bem-estar no Brasil como percentual do PIB (0,07\%), aumento do volume das exportações totais $(13,5 \%)$, e importações totais $(8,8 \%)$ difere dos de Domingues e Haddad (2006), 0,86\%, 6,4\% e 7,7\%, e Haddad et al. (2002), 0,14\%, 4,3\% e 1,7\%, respectivamente. Gurgel et al. (2002), utilizando o modelo GTAP com o ambiente econômico de 1992 encontraram um crescimento do PIB de $2 \%$ e variação no volume de exportações e importação na ordem de 28,5\% e 36\%, respectivamente.

21 Ver Castillo (2002) para uma resenha dos trabalhos que analisam o impacto da ALCA e de outros acordos comerciais sobre a economia brasileira. 
Para a simulação do Mercosul os efeitos sobre o PIB brasileiro são inferiores ao registrado por Hinojosa-Ojeda (2000), que encontrou um crescimento do PIB de 0,1\%. O impacto do Mercosul sobre o bem-estar é menor do que em outros trabalhos. O efeito do bloco sobre o bem-estar no Brasil, por exemplo, alcançou US\$ 254 milhões. Este valor é bastante inferior aos encontrados em outras simulações que utilizaram modelos de competição perfeita, com versões anteriores da base de dados do GTAP (versões 2 e 3), tais como Teixeira (1998), que chegou a US\$2,474 milhões, Ferreira Filho (1999), US\$2,390 milhões, e Teixeira e Valverde (2000), US\$2,964 milhões. O resultado, que representa 0,04\% do PIB, também é muito inferior aos registrados por Cavalcante e Mercenier (1999), que variaram entre 0,4\% e 0,49\% do PIB, embora, neste caso, a diferença também possa ser explicada pelo uso de modelos baseados em competição imperfeita. Estas tentativas anteriores de mensurar o impacto do Mercosul não separaram o efeito do bloco das medidas unilaterais aplicadas simultaneamente. Portanto, elas não puderam estimar o efeito exclusivo do Mercosul, que é o principal objetivo deste artigo. Assim, quando as medidas unilaterais são separadas da formação do bloco, o efeito líquido do Mercosul sobre o bem-estar parece ser muito menor do que os trabalhos anteriores haviam estimado.

\section{Conclusão}

Este artigo realizou duas simulações. A primeira buscou medir os efeitos da formação da ALCA a partir de 2016, enquanto a segunda procurou avaliar os impactos da consolidação do Mercosul com a convergência à TEC em 2006 sobre a produção, fluxos de comércio e bem-estar dos países ou regiões analisadas. Como as simulações se baseiam nos efeitos estáticos de 1a geração da formação dos blocos (não incorporam ganhos de escala, competição, variedade e crescimento econômico) e não consideram a eliminação de barreiras não tarifárias, se restringindo à redução e/ou eliminação de tarifas de importação, a magnitude das variações dos indicadores analisados não é muito expressiva, principalmente quando relativizados ao PIB de cada país ou região, como sugerido pela literatura.

No Brasil, a formação da ALCA provocou desvio de comércio em todos os setores analisados, especialmente em equipamento de transporte e máquinas. Isto é, as importações de fora do bloco foram substituídas por importações dos parceiros do bloco em consequência das preferências tarifárias. Já no cenário de consolidação do Mercosul ocorre o inverso, ou seja, a maior parte dos setores apresenta um aumento das importações extrabloco em detrimento das importações provenientes dos parceiros do Mercosul, situação chamada de desvio de comércio interno. A análise de bem-estar baseado na eficiência alocativa mostra que o Brasil é o país que mais se beneficia tanto com o cenário da ALCA como com o cenário Mercosul, com ganhos expressivos 
naqueles setores nos quais a redução tarifária foi mais intensa, com o setor de máquinas registrando ganhos expressivos em ambas as simulações. Os ganhos alocativos suplantam a deterioração dos termos de troca registrada em ambos os experimentos, fazendo com que o resultado agregado de bem-estar seja positivo, embora ligeiramente maior no caso da formação da ALCA. Portanto, para o Brasil as duas situações levariam a ganhos de bem-estar, com a formação da ALCA trazendo benefícios marginalmente superiores à consolidação do Mercosul, mesmo que leve a uma situação de desvio de comércio em todos os setores.

Se para o Brasil a formação da ALCA foi ligeiramente superior à implementação da TEC, o mesmo não pode ser dito para os demais parceiros do Mercosul. Enquanto a Argentina sofreu perdas de bem-estar idênticas em ambas as simulações, o Uruguai obteve resultados muito mais satisfatórios quando da consolidação do Mercosul, tendo inclusive perdas de bem-estar em razão da formação da ALCA. Os membros do NAFTA e União Europeia também apresentaram cenários antagônicos. Enquanto para os países do NAFTA a simulação ALCA trouxe benefícios superiores em relação à consolidação do Mercosul, sendo o México o país com o maior ganho de bem-estar em relação a seu PIB, o oposto ocorreu com a União Europeia, que obteve ganhos apenas com a simulação do Mercosul. Estes resultados confirmam que a liberalização discriminatória no âmbito da ALCA, devido à concessão de preferências tarifárias, traria perdas à União Europeia. Entretanto, os países do NAFTA se beneficiariam em razão do acesso privilegiado aos demais países do hemisfério, que concederiam reduções tarifárias mais significativas que as concedidas por eles, gerando melhorias dos termos de troca, especialmente para Estados Unidos e México.

\section{Referências}

ALLEN, C. \& GASIOREK, M. \& SMITH, A. (1996). Trade creation and trade diversion: Competitiveness impacts of the single market programme. Brighton: School of European Studies, University of Sussex.

BALDWIN, R. \& VENABLES, A. (1995). “Regional economic integration.” In: GROSSMAN, G. \& ROGOFF, K. (eds.). Handbook of International Economics. Amsterdam: North Holland, 3:1597-1644.

BANCO MUNDIAL. (2000).Trade Blocs. Washington: Oxford University Press.

BRANDÃO, A. \& LOPES, M. \& PEREIRA, L. (1998). “Uma análise quantitativa dos impactos do Mercosul sobre o Brasil.” In: BRANDÃO, A. \& PEREIRA, L. (eds.). Mercosul: Perspectivas da Integração. Rio de Janeiro: Fundação Getúlio Vargas, pp.47-74.

BROWN, D. \& DEARDORFF, A. \& STERN, R. (1992). A North-American free trade agreement: Analysis issues and a computational assessment. The World Economy, 15:15-29. 
CASTILlO, M. (2002). Impactos de acordos comerciais sobre a economia brasileira: Resenha dos trabalhos recentes. Texto para Discussão do IPEA 936, Rio de Janeiro: IPEA.

CAVALVANTE, J. \& MERCENIER, J. (1999). "Uma avaliação dos ganhos dinâmicos do Mercosul usando equilíbrio geral.” Pesquisa e Planejamento Econômico, 29:153-184.

DOMINGUES, E. \& HADDAD, E. (2006). "Impactos setoriais e regionais da Alça: projeções para economia brasileira.” Pesquisa e Planejamento Econômico, 6:255-288.

ETHIER, W. (1998). “The new regionalism.” The Economic Journal, 449:11491161.

FERREIRA FILHO, J. (1999). “Trade creation $x$ trade diversion: Evidences from the GTAP model in the Mercosur integration process." Paper Presented at the Second Annual Conference on Global Economic Analysis, Denmark.

FLORES, R. (1997). “The gains from Mercosur: a general equilibrium, imperfect competition evaluation.” Journal of Policy Modeling, 19:1-18.

FRANCOIS, J. (1998). "Scale economies and imperfect competition in the GTAP model.” GTAP Technical Paper, no 14, Center for Global Trade Analysis, Purdue University.

GEHLHAR, M. (1997). "Historical analysis of growth and trade patterns in the Pacific Rim: An evaluation of the GTAP framework.” In: HERTEL, T. (ed.). Global Trade Analysis: Modelling and Applications. New York: Cambridge University Press, pp.349-363.

GOHIN, A. \& HERTEL, T. (2001). "A note on the CES functional form and its use in the GTAP model. Centre for Global Trade Analysis, Purdue University. URL: http://ae761-e.agecon.purdue.edu/gtap/resources/download/449. pdf.

GURGEL, A \& BITENCOURT, M. \& TEIXEIRA, E. (2002). "Impactos dos acordos de liberalização comercial Alca e Mercoeuro sobre os países membros.” Revista Brasileira de Economia, 56:335-369.

HAALAND, J. \& NORMAN, V. (1992). "Global production effects of European integration.” In: WINTERS, L. A. (ed.). Trade flows and trade policy after 1992. Cambridge: Cambridge University Press.

HADDAD, E \& DOMINGUES, E. \& PEROBELLI, F. (2002). "Regional effects of economic integration: the case of Brazil." Journal of Policy Modeling, 24:453-482.

HARRISON G. \& RUTHERFORD, T. \& TARR, D. (1994). "Products standards, imperfect competition and the completion of the market of European Community." World Bank mimeo, no 6, Washington DC.

HARRISON G. \& RUTHERFORD, T. \& TARR, D. (1997). "Quantifying the Uruguay Round.” The Economic Journal, 107:1405-1430.

HERTEL, T. (1997). Global trade analysis: modelling and applications. New York: Cambridge University Press. 
HERTEL, T. \& MARTIN, W. (1999). Would developing countries gain from inclusion of manufactures in the WTO negotiations? Paper presented at Conference on WTO and the Millennium Round, Geneva.

HINOJOSA-OJEDA, R. (2000). Brazil and the United States at the Gateway of the FTAA: A CGE Modeling Approach to Challenges and Options. Paper Presented in Economia Brasileira e os Processos de Integração Subregional e Hemisférico, IPEA-Instituto de Pesquisa Econômica, Ministério do Planejamento e Orçamento, Brasilia, Brazil.

HOEKMAN, B. \& SCHIFF, M. \& WINTERS, L. A. (1998). "Regionalism and development: Main messages from a World Bank research project.” Development Research Group, Washington DC: World Bank.

JACQUEMIN, A. \& SAPIR, A. (1988). "European integration or world integration.” Weltwirschaftliches Archiv, 124:127-139.

LAWRENCE, R. (1997). "Preferential trading arrangements: the traditional and the new." In: GALAL, A. \& HOEKMAN, B. (eds.). Regional Partners in Global Markets. CEPR, Egypt: The Egyptian Center for Economic Studies, World Trade Center, pp.13-34.

MALCOLM, R. (1998). “Adjusting tax rates in the GTAP Data Base.” GTAP Technical Paper, no 12, Center for Global Trade and Analysis, Purdue University. URL: http://www.agecon.purdue.edu/gtap/techpapr.

MCDOUGALL, R. (1993). “Two small extensions to Salter.” Salter Working Paper $\mathrm{n}^{\circ} 12$.

MCDOUGALL, R. \& ELBEHRI, A. \& TRUONG, T. (1998). Global trade, assistance and protection: The GTAP 4 DataBase. Purdue University: Center for Global Trade and Analysis.

PANAGARIYA, A. (1997). An empirical estimate of static welfare losses to Mexico from NAFTA. Center for International Economics, University of Maryland.

ROLAND-HORST, D. \& REINERT, K. \& SHIELLS, C. (1992). "North-American trade liberalisation and the role of nontariff barriers." In: Economy-wide modelling of the economic implications of a FTA with Mexico and a NAFTA with Mexico and Canada. U.S. International Trade Commission Publication, no 2508.

SAPIR, A. (1992). "Regional Integration in Europe.” The Economic Journal, 102:1491-1506.

TEIXEIRA, E. (1998). Impact of the Uruguay round agreement and Mercosur on the Brazilian economy. Revista Brasileira de Economia, 52:441-462.

TEIXEIRA, E. \& VALVERDE, S. (2000). "Impacts of Mercosur, Nafta and WTO round agreements on the economies of Argentina, Brazil and Chile." In: Annual Conference on Global Economic Analysis, 2000, Melbourne, Australia. Proceedings. Clayton, Australia: The Centre of Policy Studies, Monash University.

TRUMAN, E. (1975). "The effects of European Economic Integration on the production and trade of manufactured products.” In: BALASSA, B. (ed.). European Economic Integration. Amsterdam: North Holland, pp.3-40. 
VINER, J. (1950). The Custom Union Issue. London: Carnegie Endowment for International Peace.

WATANAKE, M. \& MONTEAGUDO, J. (2001). "Regional trade agreements for Mercosur: The FTAA and the FTA with the European Union.” Artigo apresentado no Seminário Impacts of Trade Liberalization Agreements on Latin America and the Caribbean, Washington: CEPII e BID (orgs.).

WINTERS, L. A. (1997). "Regionalism and the rest of the world: The irrelevance of the Kemp-Wan theorem." Oxford Economic Paper, 49:228-234.

Recebido em: 23 de abril de 2009 Primeira resposta em: 01 de setembro de 2009

Aceite em: 19 de novembro de 2009

\section{Anexo: As Principais Características do Modelo GTAP}

O modelo GTAP de comércio mundial (Hertel 1997) é um modelo padrão, multi-regional de equilíbrio geral aplicável que assume retornos constantes de escala e competição perfeita nas atividades de produção. ${ }^{22}$ A versão 4 da base de dados do GTAP (McDougall et al. 1998) contempla 45 regiões e 50 setores que podem ser agregados conforme o interesse do pesquisador. $\mathrm{O}$ componente básico do projeto consiste em sua base de dados, que contém informações relativas ao comércio bilateral, transporte, tarifas e informações insumo-produto específicas que permitem mapear as interligações setoriais em cada região. Os gastos de uma determinada região são orientados por uma função utilidade Cobb-Douglas agregada que aloca os gastos em três categorias: privados (PRIVEXP), públicos (GOVEXP) e poupança (SAVE). $\mathrm{Na}$ abordagem padrão, a função utilidade agregada assegura a participação de cada categoria na restrição orçamentária regional. 
FIGURA A.1. FLUXO DE RENDA EM UMA ECONOMIA FECHADA PARA O MODELO GTAP

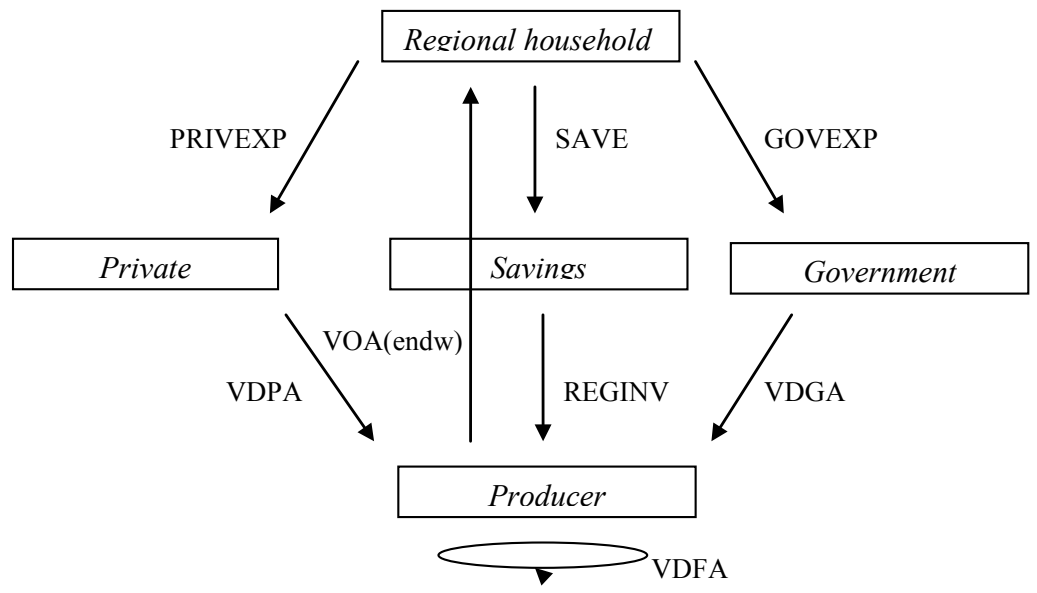

FONTE: HERTEL, T. (Org.) Global Trade Analysis. 1997. p. 16.

Os fluxos da Figura A.1 assumem a ausência de taxas. A fonte de renda de determinada região (Regional household) compreende a "venda" da dotação natural de commodities (terra, capital e trabalho) para as firmas. A renda da região é representada por VOA(endw), que denota o valor do produto a preços de fatores. As firmas (Producer) combinam essa dotação de commodities com bens intermediários (VDFA - valor das compras domésticas pelas firmas a preços de fatores) para produzir bens finais. Esse processo envolve vendas às unidades familiares (Private household) e ao governo (Government), e a venda de bens de investimento (Savings) para suprir a demanda por poupança.

Ao acrescentar-se o Resto do Mundo (ROW) à análise (Figura A.2), ainda assumindo-se a ausência de taxas, incorpora-se uma fonte de importações e um destino de exportações dos bens finais regionais. As importações representam pagamentos dos agentes regionais para o resto do mundo. Ao mesmo tempo, introduz-se o setor Global Bank para intermediar a poupança do resto do mundo e os investimentos regionais. O segundo setor a ser introduzido é o de comércio internacional e atividades de transporte, que contempla exportações regionais, transporte e serviços de seguros, e produz um bem composto utilizado para fazer circular o comércio entre regiões. O valor desse bem consiste na diferença entre o valor fob das exportações e o valor cif das importações globais. 
FIGURA A.2. ESQUEMA DE UMA ECONOMIA ABERTA NO MODELO GTAP

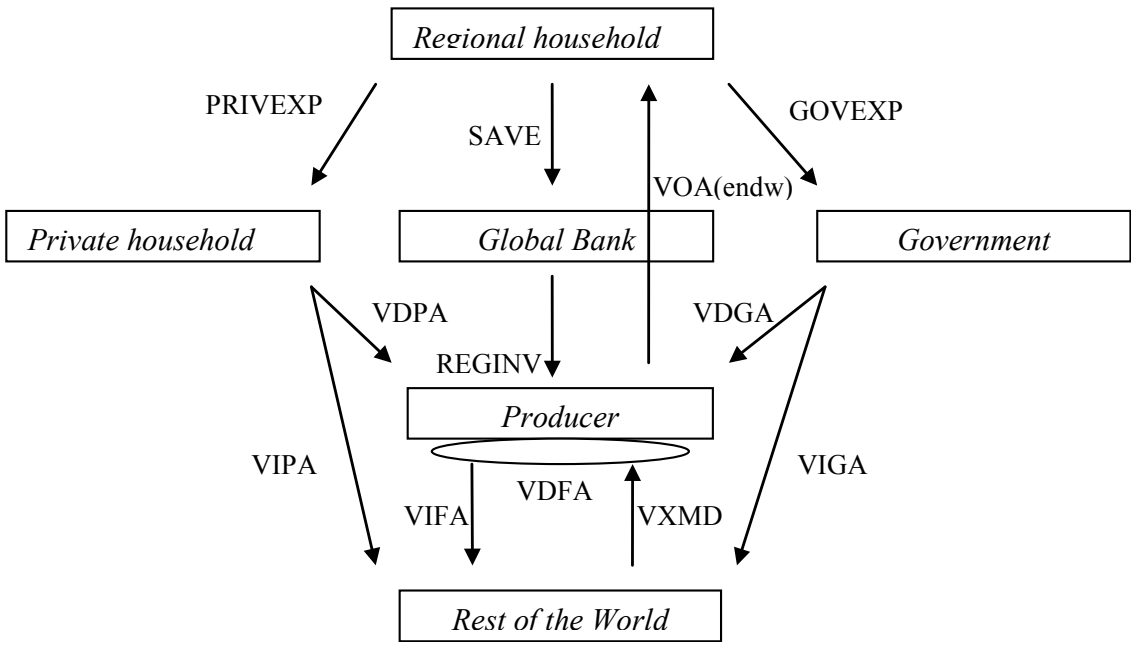

FONTE: HERTEL, T. (Org.) Global Trade Analysis. 1997. p. 17.

A inclusão de taxa sobre a produção, denotada no modelo GTAP por PTAX (i,r), leva ao valor da produção a preços de mercado, VOM (i,r). VOM deve ser igual à soma do valor das vendas domésticas a preços de mercado, VDM (i,r), e o valor das exportações da commodity "i” originárias da região " $r$ " a preços de mercado doméstico, destinada à região "s", $\operatorname{VXMD}(i, r, s)$.

As unidades familiares despendem sua renda em compras de bens produzidos internamente (valor das compras de unidades familiares a preços de fatores, VDPA $(i, s)$ ) e em bens externos (VIPA $(i, s)$ ). Deduzindo-se as taxas de importação e domésticas, $\operatorname{IPTAX}(i, s)$ e $\operatorname{DPTAX}(i, s)$, obtém-se os valores respectivos a preços de mercado, $\operatorname{VIPM}(i, s)$ e $\operatorname{VDPM}(i, s)$.

As firmas demandam insumos internos e externos, nos montantes VDFA ( $i, j$, $s)$ e VIFA $(i, j, s)$. Ajustando-se as taxas intermediárias da produção, obtém-se os valores a preços de mercado, $\operatorname{VDFM}(i, j, s)$ e $\operatorname{VIFM}(i, j, s)$. As firmas também compram serviços de commodities non-tradable, referentes à dotação natural de commodities da região fornecida pelas unidades familiares. Algebricamente, os gastos totais da região $r$ são dados por:

$$
\Sigma[\operatorname{VPA}(i, r)+\operatorname{VGA}(i, r)+\operatorname{SAVE}(r)]
$$

Na equação A1, VPA $(i, r)$ representa o valor dos gastos privados agregados da região $r$ na commodity $i$, VGA $(i, r)$ denotas os gastos públicos totais da região $r$ na commodity $i$, e $\operatorname{SAVE}(r)$, a poupança líquida da região $r$. 
Os setores globais compreendem o setor de transportes internacionais, fornecidos pelas economias regionais e "exportados" para o setor global de transportes, e o setor de intermediação financeira internacional. Supõe-se que esse último setor fornece um bem de investimento composto, baseado em um portfólio de "investimento regional líquido", e o oferece aos demandantes internacionais de poupança.

\section{Produção}

O modelo usa uma estrutura de ninho de três níveis na especificação da função de produção (Figura A.3). No topo, a função de produção assume substitutibilidade zero entre os fatores primários de produção e os insumos intermediários (tecnologia de Leontief). Assim, o mix ótimo de fatores primário é independente dos preços dos insumos intermediários, enquanto o mix ótimo de insumos intermediários não varia com o preço dos fatores primários. ${ }^{23}$

\section{FIGURA A.3. ESTRUTURA PRODUTIVA DO GTAP}

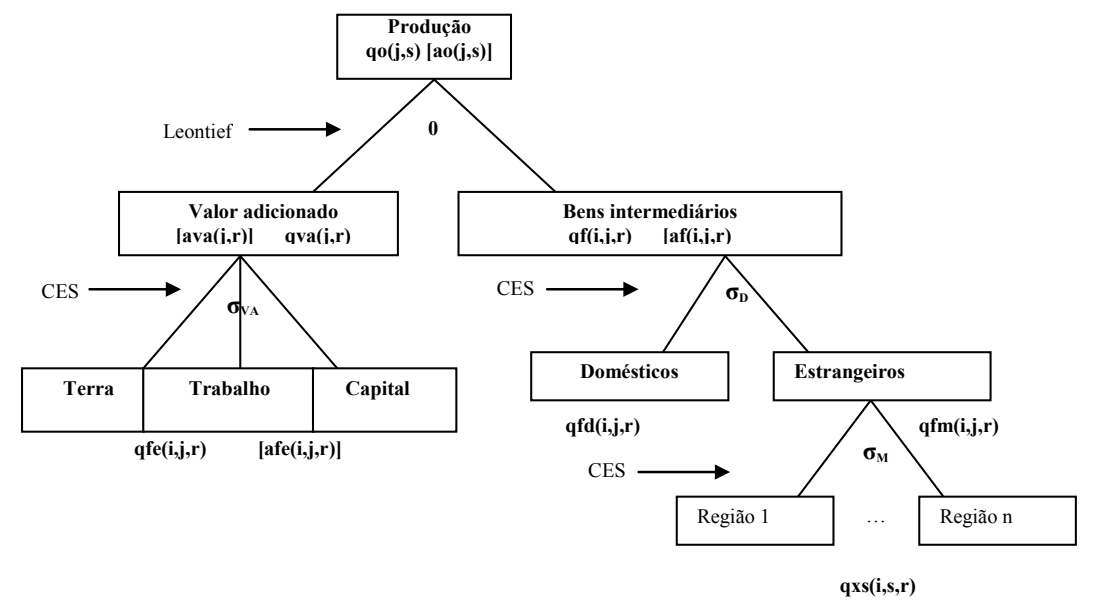

FONTE: Hertel, 1997.

O segundo nível envolve uma elasticidade de substituição constante tanto entre os insumos intermediários como entre os fatores de produção ( $\sigma \mathrm{VA})$. Assume-se que os insumos importados são diferenciados por origem $(\sigma \mathrm{M})$, assim como os insumos domésticos são discriminados em relação aos importados $(\sigma D)$. Isto é, as firmas inicialmente determinam o mix ótimo de insumos domésticos e importados e somente depois decidem a respeito da origem das 
importações (hipótese de Armington). ${ }^{24} \mathrm{O}$ nível mais baixo do ninho também assume uma elasticidade de substituição constante entre insumos importados de diferentes origens.

\section{Mudança tecnológica no GTAP}

Para ilustrar como um choque tecnológico pode afetar as variáveis do modelo, apresentam-se as equações (A2) e (A3). Essas equações descrevem o ninho do valor adicionado da árvore tecnológica. Especificamente, elas explicam como as variações nos preços do grupo valor-adicionado ( $p v a)$ e na demanda condicional ( $q f e$ ) para os fatores capital, terra e trabalho em cada setor. O coeficiente $S V A(i, j, r)$ refere-se à participação do fator $i$ no custo total do valor-adicionado no setor $j$ da região $r$.

$$
\begin{aligned}
& p v a(\mathrm{j}, \mathrm{r})=\sum_{\mathrm{k} \in \mathrm{ENDW}} \mathrm{SVA}(\mathrm{i}, \mathrm{j}, \mathrm{r}) \cdot[p f e(\mathrm{i}, \mathrm{j}, \mathrm{r})-a f e(\mathrm{i}, \mathrm{j}, \mathrm{r})] \\
& q f e(\mathrm{i}, \mathrm{j}, \mathrm{r})+a f e(\mathrm{i}, \mathrm{j}, \mathrm{r})=q v a(\mathrm{j}, \mathrm{r})-\sigma_{\mathrm{VA}}(\mathrm{j}) \cdot[p f e(\mathrm{i}, \mathrm{j}, \mathrm{r})-a f e(\mathrm{i}, \mathrm{j}, \mathrm{r})-p v a(\mathrm{j}, \mathrm{r})
\end{aligned}
$$

As equações também incluem variáveis que governam a taxa de melhora tecnológica do fator primário, afe $(i, j, r)$. Essa taxa representa a variação efetiva do insumo primário $i$ no setor $j$ da região $r$. Como um valor de afe $(i, j, r)$ $>$ o resulta em um declínio no preço efetivo do fator primário $i$, o mesmo aparece nas equações como uma dedução de $p f e(i, j, r)$ e, portanto, tem as seguintes implicações: a) encorajar a substituição do insumo primário $i$ por outros insumos primários. Isso pode ser ilustrado através da observação do lado direto da igualdade da equação (A3); b) diminuição da demanda pelo insumo $i$, através do lado esquerdo da mesma equação; c) redução do custo para o grupo valor-adicionado via a equação (A2).

No nível superior da árvore tecnológica invertida tem-se a demanda pelo composto valor-adicionado e insumos intermediários. Como o modelo não admite substituição entre intermediários e valor-adicionado ${ }^{25}$, o efeito substituição causado pelo preço relativo é suprimido, ficando apenas o efeito expansão. Nesse nível da árvore tecnológica existem três tipos de mudança tecnológica. As variáveis ava $(j, r)$, e $a j(i, j, r)$ referem-se, respectivamente, às mudanças tecnológicas nos insumos dos grupos valor-adicionado e intermediários. A variável ao $(j, r)$ refere-se à mudança tecnológica Hicks-neutra. Essa última reduz o requerimento de insumo associado à produção de um dado nível de produto.

\footnotetext{
24 A estrutura de preferências de Armington implica que um bem produzido em uma região é um substituto imperfeito para bens produzidos pela mesma indústria em outras regiões. Ou seja, a mesma commodity, de diferentes fontes, pode ser comercializada a preços diferentes.

25 Essa simplificação resulta da suposição do modelo que assume uma função Leontief nesse nível de produção.
} 


\section{Consumo}

Em relação à função de utilidade, o modelo usa uma estrutura de ninho em quatro níveis. O nível mais elevado da demanda final é governado por uma função de utilidade agregada do tipo Cobb-Douglas, em que a renda é destinada ao consumo privado, aos gastos do governo e à poupança. Portanto, cada uma destas categorias apresenta uma parcela fixa na renda total. ${ }^{26} \mathrm{Uma}$ vez que a mudança nos gastos foi determinada o próximo passo consiste em alocá-los entre os bens agregados. Isto é feito no segundo nível do ninho de demanda no qual as despesas do governo são ditadas por uma função Cobb-Douglas enquanto os gastos privados agregados são modelados por uma forma funcional não homotética CDE (constant difference elasticity). Esta forma de função de utilidade implica que sucessivos aumentos no consumo privado de determinados bens ou serviços não gera necessariamente melhorias equi-proporcionais no bem-estar econômico. Assim que a demanda agregada por importações é determinada o restante das árvores de utilidade de ambos, governo e setor privado, é análogo ao segundo e terceiro níveis da demanda das firmas por insumos intermediários, sendo baseada em uma função de utilidade com elasticidade de substituição constante. A única diferença entre a demanda por importações agregadas entre firmas e famílias são as suas respectivas parcelas nas importações. Em consequência, os setores (e famílias) que são mais intensivos no uso de importações serão mais afetados pelas mudanças nas tarifas de importação.

Cada nível das funções de utilidade e produção compreende dois tipos de equações: equação agregada de preços (A4), e um conjunto de equações de demanda condicionais (A5). Assumindo uma função de produção com somente dois insumos, resolvendo o problema de minimização de custos do produtor e descartando os termos associados às mudanças técnicas, as duas equações podem ser expressas na sua forma linear da seguinte forma, respectivamente:

$$
\begin{aligned}
& \hat{c}=\theta_{1} \hat{p}_{1}+\left(1-\theta_{2}\right) \hat{p_{2}} \\
& \hat{q_{1}}=\hat{y}-\sigma\left(\hat{c}-\hat{p}_{1}\right)
\end{aligned}
$$

onde: ${ }^{27}$

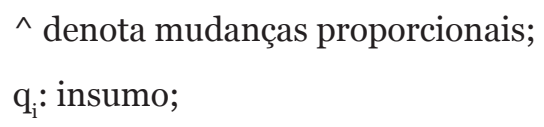

26 Entretanto, há alguma discrição sobre a alocação das despesas. As compras e poupança reais do governo, por exemplo, também podem ser consideradas variáveis exógenas, situação na qual as despesas privadas se ajustam para satisfazer a restrição do orçamento regional.

27 Gohin \& Hertel (2001) fornecem a derivação completa das equações (3) e (4) através do problema de minimização de custos do produtor. 
$\mathrm{p}_{\mathrm{i}}$ : preço do insumo;

y: produção;

$\mathrm{c}_{\mathrm{y}}$ : custo unitário;

$\sigma$ : elasticidade de substituição constante;

$\theta$ : parcela dos insumos nos custos;

efeito expansão $=\hat{y}$, i.e. o efeito da mudança no nível de produção;

efeito substituição $=\sigma\left(\hat{c_{i}}-\hat{p_{i}}\right)$, i.e. o efeito da mudança nos preços relativos.

Mesmo quando o número de insumos aumenta para um número superior a dois, a forma das equações acima não se altera. Aplicando estas fórmulas para o ninho agregado das importações (o nível mais baixo das funções de produção e utilidade) produz a equação A4.1, que explica a mudança percentual no preço agregado das importações e equação A5.2 que determina a fonte das importações:

$$
\begin{aligned}
& \operatorname{pim}(i, s)=\sum_{k \in R E G} \operatorname{MSHRS}(i, r, s) \times \operatorname{pms}(i, r, s) \\
& q x s(i, r, s)=\operatorname{qim}(i, s)-\sigma_{M}(i) \times[\operatorname{pms}(i, r, s)-\operatorname{pim}(i, s)]
\end{aligned}
$$

$\operatorname{MSHRS}(i, r, s)=\left(\frac{\operatorname{VIMS}(i, r, s)}{\sum_{r \in R E G} \operatorname{VIMS}(i, r, s)}\right)$

onde:

pim (i,s): preço de mercado das importações agregadas i na região s;

pms (i,r,s): preço doméstico do bem i fornecido pela região r para a região s;

MSHRS: a parcela de mercado da região r nas importações agregadas do bem i na região s avaliado a preços de mercado;

VIMS (i,r,s): valor das importações do bem i da região r para a região s avaliado a preços de mercado do exportador;

qxs (i,r,s): exportações do bem i da região r para a região s;

qim (i,s): importações agregadas do bem i na região s, ponderado pelos preços de mercado;

$\sigma_{M}(i)$ : elasticidade de substituição de importação do bem i. 
O preço doméstico do bem i fornecido pela região $\mathrm{r}$ para a região $\mathrm{s}$ (pms) é diretamente afetado pelas mudanças tanto nas tarifas de importação promovidas pelo país importador (tms) quanto pelo preço cif das importações (pcif) como descrito abaixo:

pms $(\mathrm{i}, \mathrm{r}, \mathrm{s})=\operatorname{tms}(\mathrm{i}, \mathrm{r}, \mathrm{s})+\operatorname{pcif}(\mathrm{i}, \mathrm{r}, \mathrm{s})$

\section{Investimento e Poupança}

O modelo também inclui um banco global que intermedia a poupança e os investimentos globais, vendendo bens de poupança para cada família regional para satisfazer suas demandas por poupança e comprando ações no portfólio de investimentos regionais. Como mencionado acima, a poupança é um argumento na função de utilidade das famílias e a otimização condicionada leva à demanda por bens de poupança, que assim como todos os demais bens dependem do nível de renda das famílias e do seu preço relativo. Uma vez que o banco global reuniu todas as poupanças regionais há duas abordagens pelas quais o banco pode alocar os investimentos regionais. A primeira, chamada de composição regional fixa (que é empregada em todas as simulações neste artigo), assume que a composição regional do estoque de capital global fica inalterada na simulação. Desta forma, os investimentos regionais e globais se movem juntos e as taxas de retorno em cada região serão diferentes. $\mathrm{O}$ segundo mecanismo (componente da taxa de retorno) é uma abordagem de investimento alternativa na qual as taxas de retorno são idênticas em todas as regiões. $\mathrm{O}$ investimento depende da taxa esperada de retorno no período seguinte que declina assim que o estoque de capital aumenta. Os investimentos são alocados de forma que alterações na taxa esperada de retorno sejam equalizadas entre as regiões.

O componente do bem-estar, investimento-poupança (I-S) sobre o bem-estar, por sua vez, é função dos preços da poupança e investimento e da situação como determinada região aparece no saldo de poupança líquida. O bem-estar resultante dessa relação entre poupança e investimento (I-S) é calculado no modelo como a diferença entre o investimento líquido da região em questão, multiplicado pelo preço dos bens de capital nessa região, e a poupança multiplicada pelo seu respectivo preço. Portanto, os ofertantes líquidos de poupança ao banco global se beneficiam do incremento dos preços da poupança em relação aos produtos de investimento.

Por fim, há um setor de transporte internacional, que intermedia a demanda e a oferta por serviços de transportes internacionais. Devido à ausência de informações que ligue as exportações de serviços de transporte com rotas específicas, o modelo combina estes serviços em um único setor agregado. $\mathrm{O}$ valor destes serviços representa a diferença entre o preço cif e o preço fob. 
Os experimentos são conduzidos a partir de uma closure denominada 'novo equilíbrio geral multi-regional' (New MRGE), em que a produção, preços e renda são endógenos para todas as regiões enquanto a população e as variáveis de mudança técnica e de políticas são exógenas ao modelo. Esta closure é apropriada para captar a substituição na produção e consumo entre os setores que ocorrem devido à liberalização comercial. A chamada "composição fixa regional" é adotada em todas as simulações, assumindo-se que a composição regional do estoque mundial de capital permanece inalterada (rordelta $=0$ ) ${ }^{28}$ Como o objetivo é mensurar os efeitos da formação da ALCA e da consolidação do Mercosul, os experimentos envolvem somente as mudanças nas tarifas de importação adotadas pelos países do bloco sem que haja reciprocidade dos países não membros. retorno). 
